\title{
Editorial
}

\section{Tread Carefully}

\author{
Arifa Savanur \\ Neuromuscular Research Unit, Department of Physiology, University of Karachi, \\ Karachi, Pakistan
}

Epilepsy is highly prevalent neurologic disorder with poor understanding of pathophysiology and identified treatment strategy. It is characterized by recurrent seizures, due to abnormal neuronal firing with numerous causes that have underlying brain dysfunction. Our central nervous system consists of 100 billion neurons with profuse interconnection amongst each other particularly those of cerebral cortex (4). Activity of one neuron influence the neighbouring cells, which feed directly or after a few more relays back to the original cells. If the inter-connections were all the excitatory the system would quickly degenerate into uncontrolled positive feedback oscillation, so an abundance inhibition is necessary (3). When this inhibition is disturbed, large numbers of neurons discharge in synchrony to exhibit immense electrical surge in brain that culminates in epilepsy. There are different types of epilepsies, and they have many causes, but for up to half of people with epilepsy the cause is unknown (2). It is estimated that about $0.5-1 \%$ of the population is diagnosed with epilepsy worldwide, however, only in Pakistan approximately 1.38 million people are suffering from epilepsy with overall prevalence of 9.99 per 1000 population (6). Epilepsy is highly stigmatized disorder in Pakistan because of lack of education and socio-economic conditions. Knowledge about epilepsy and its care is extremely low as only about $27.5 \%$ epileptic persons in urban areas and $1.9 \%$ in the rural areas is being treated with antiepileptic drugs (6). Medical therapy is the mainstay, with most patients well controlled on a single anti epileptic drugs (AED). More than 30 percent of epileptic patients have refractory epilepsy that is not controlled by two or more appropriately chosen AED or other therapies. The condition itself and need of multiple medication regimes often affects patient's social, cognitive, and interpersonal relationships that prevent them to live independently as they need help in case of an electrical surge that collapse them on ground. In this context of medications the vagus nerve stimulation (VNS) has been used to provide a therapeutic option, if patient's seizures are not controlled by AEDs. According to National health survey done in USA (12), it is concluded that an important clinical hinders in seizures control is the poor socioeconomic condition such as low income, unemployment, and being divorced or widowed or socially an unbalanced family. Further, if a person is having trouble taking medications regularly or has other lifestyle factors not controlling seizures, counselling and education about trigger management would be needed first. Recent studies in the field of the neuro-gastroenterology report that, in fact, about 80 to $90 \%$ of the signals passing along the vagus nerve are not coming from brain, but from the enteric nervous system of the gut and electrical stimulation of the vagus nerve mimic these signals therefore useful for the treatment of depression, epilepsy and obesity (1). The clinical use of VNS in epilepsy was first described in 1990 by Pérez-Carbonell in Practical Neurology, it has evolved a place in the treatment pathway of refractory focal epilepsy and refractory generalized seizures (8). In 1997 United States allow the use of VNS for refractory epilepsy (9). Currently, in Feb $19^{\text {th }} 2021$ good news came from Lahore that the stimulator has been implanted on vagus nerve of two female epileptic patients by Dr. Asif Bashir at Bashir Neuro spine institute, Lahore (10). They claimed that this was first done in Pakistan with the cost of around Rs 2.5 million, which is the cheapest in the world. The report published in daily 'News' also said that the patient were released from hospital after 3 to $4 \mathrm{hr}$ of surgeries, both the patients were suffering from drug-resistant epilepsy or refractory or uncontrolled or intractable epilepsy. The evidences of the use of 
long term efficacy of VNS therapy are still limited and controversial (5).Vagus nerve is the most important $10^{\text {th }}$ pair of cranial nerve serves as the body's superhighway, carrying information between the brain and the internal organs and controlling the crucial bodily function including control of mood, immune response, digestion, and heart rate. Due to its wide distribution the reported side effects of VNS are also complex include, hoarseness or changes in voice, sore throat, shortness of breath, coughing, slow heart rate, difficulty swallowing, stomach discomfort or nausea. Although no definite conclusion can be drawn as outcome difference with respect to VNS and use of positive predictive markers such as High mobility group box-1 or micro RNA (7) that have been under investigation with reduction in seizures frequency and decremented medication regime (11). Thus for Pakistan it is also necessary that a neurologist or an epilepsy specialist should promptly assess first and would review the types of medicines and make sure that the correct drugs for the right type of seizures rather going to VNS therapy as its mechanism is not really clear and requires a thorough investigation and further clinical trials to identify its protective effects for restoring health and to draw a definitive conclusion.

\section{References:}

1. de Lartigue G. (2016). Role of the vagus nerve in the development and treatment of diet-induced obesity. The Journal of Physiology 594(20),5791-5815. https://doi.org/10.1113/JP271538

2. do Canto A.M., Amanda, D., Geraldis Jaqueline C., Godoi Alexandre B., da Rosa Douglas C., Lopes-CendesIscia (2021). Neuroproteomics in Epilepsy: What Do We Know so Far? Frontiers in Molecular Neuroscience. 254(13). Front. Mol. Neurosci., o7 January 2021 | https://doi.org/10.3389/fnmol.2020.604158

3. Gidon, A., Zolnok, T.A., Fidzinski, P., Bolduan, F., Papoutsi, A., Poirazi, P. Holtkamp, M., Vida, I. Larkum, M. (2020). Dendritic action potentials and computation in human layer 2/3 cortical neurons. Science. 367. 83-87. 10.1126/science.aax6239.

4. Herculano-Houzel Suzana (2009). The human brain in numbers: a linearly scaled-up primate brain. Frontiers in Human Neuroscience 31(3) https://www.frontiersin.org/article/10.3389/neuro.09.031.2009

5. Kawai K, Tanaka T, Baba H, Bunker M, Ikeda A, Inoue Y, Kameyama S, Kaneko S, Kato A, Nozawa T, Maruoka E, Osawa M, Otsuki T, Tsuji S, Watanabe E, Yamamoto T. Outcome of vagus nerve stimulation for drug-resistant epilepsy: the first three years of a prospective Japanese registry. Epileptic Disord. 2017 Sep 1;19(3):327-338. doi: 10.1684/epd.2017.0929. PMID: 28832004.

6. Khatri I.A, Iannaccone ST, Ilyas MS, Abdullah M, Saleem S. (2003). Epidemiology of epilepsy in Pakistan: Review of literature. J Pak Med Assoc. 53(12):594-7. PMID: 14765939. https://pubmed.ncbi.nlm.nih.gov/14765939/

7. Kobylarek, D., Iwanowski, P., Lewandowska, Z., Limphaibool, N., Szafranek, S., Labrzycka, A. And Kozubski, W. (2019). Advances in the Potential Biomarkers of Epilepsy. Front. Neurol. 10:685.doi: 10.3389/fneur.2019.00685.

8. Krahl, S. E. (2012). Vagus nerve stimulation for epilepsy: A review of the peripheral mechanisms. Surgical neurology international, 3 (Suppl 1), S47-S52. https://doi.org/10.4103/2152-7806.91610.

9. Pérez-Carbonell, L., Faulkner, H., Higgins, S. et al. (2019) Vagus nerve stimulation for drug-resistant epilepsy. Practical Neurology. http://dx.doi.org/10.1136/practneurol-2019002210 .

10. Raza, A. (2021) Report 20 February 2021. First-ever surgeries to treat epilepsy done in Pakistan. https://www.thenews.com.pk/print/792938-first-ever-surgeries-to-treat-epilepsy- 
done-in-

pakistan\#: :text=LAHORE\%3A\%20To\%20treat\%20chronic\%20epilepsy,time\%20in\%20the $\% 20$ country\%20successfully

11. Surges, R., Kretschmann, A., Abnaof, K., van Rikxoort, M., Ridder, K., Fröhlich, H., et al. (2016). Changes in serum miRNAs following generalized convulsive seizures in human mesial temporal lobe epilepsy. Biochem Biophys Res Commun. 481:13-8.

doi: 10.1016/j.bbrc.2016.11.029.

12. Tian, N \& Boring, Michael \& Kobau, Rosemarie \& Zack, Matthew \& Croft, Janet. (2018). Active Epilepsy and Seizure Control in Adults - United States, 2013 and 2015. MMWR. Morbidity and mortality weekly report. 67. 437-442. http://dx.doi.org/10.15585/mmwr.mm6715a1external icon.

\section{Arifa Savanur (Dr)}

Assistant Professor \& in charge of Neuromuscular Research Unit, Department of Physiology, University of Karachi,

Karachi, Pakistan

Email:

asavanur@uok.edu.pk

arifa.savanur@gmail.com 